\title{
Populações de plantas na cultura da soja em cultivares convencionais e Roundup Ready ${ }^{\mathrm{TM}}$
}

\author{
Marcos Paulo Ludwig', Luiz Marcelo Costa Dutra², Orlando Antônio Lucca Filho, Lucio Zabot', \\ Adilson Jauer ${ }^{5}$ Daniel Uhry ${ }^{6}$
}

\section{RESUMO}

Este trabalho teve como objetivo estudar o comportamento de cultivares de soja convencionais e Roundup Ready ${ }^{T M}$ (RR) quando cultivados com diferentes populações de plantas por hectare. Foram realizados três ensaios no município de Jari, RS: em novembro de 2004 e de 2005 e em janeiro de 2006 (semeadura após a época indicada). Os cultivares convencionais utilizados foram: CEP/CD 41, CD 201, FUNDACEP 39 e CD 205 e os Roundup Ready ${ }^{T M}$ AL72, NK Mágica 7.3 RR e A 6001 RG nas populações de 250, 400 e 550 mil plantas ha-1 ${ }^{-1}$ Em cada ensaio, o delineamento experimental utilizado foi blocos ao acaso, com 21 tratamentos e quatro repetições. Os tratamentos foram dispostos em esquema de parcelas subdivididas, representados pelos cultivares nas parcelas e pelas populações de plantas nas subparcelas. Foram avaliados a produtividade de grãos e os componentes da produção: legumes por planta e por $\mathrm{m}^{2}$, peso de 100 grãos e número de grãos por legume. O comportamento dos cultivares convencionais e Roundup Ready ${ }^{T M}$ diferiu com a população de plantas. Em condição de estresse hídrico severo o aumento da população de plantas não afetou a produtividade. Somente o cultivar A 6001 RG apresentou rendimento estável nas diferentes populações de plantas, indicando que ele possui maior plasticidade. O número de legumes por planta foi reduzido com o aumento do número de plantas por área. As maiores produtividades foram alcançadas onde foi constatado maior número de legumes por $\mathrm{m}^{2}$. O maior valor do peso de 100 grãos foi encontrado na maior população de plantas. O número de grãos por legume reduziu-se com o aumento da população de plantas. Condições de cultivo mais favoráveis tendem a aumentar o número de legumes $/ \mathrm{m}^{2}$, peso de 100 sementes e número de grãos por legume.

Palavras-chave: Glycine max L. (Merrill), componentes do rendimento, densidade de semeadura, produtividade de grãos, soja transgênica.

\section{ABSTRACT}

\section{Soybean plant stand in conventional cultivars and Roundup Ready ${ }^{T M}$}

This study aimed to evaluate the performance of conventional and Roundup Ready ${ }^{T M}$ soybean when subjected to different plant stands. Three trials were conducted in the municipality of Jari-RS, the first in November 2004, the second in November 2005 and the last in January 2006 (after the recommended time). The conventional cultivars 'CEP/CD 41', 'CD 201', 'Fundacep 39', 'CD 205' and the Roundup Ready ${ }^{T M}$ 'AL72', 'NK Mágica 7.3 RR' and 'A 6001 RG' were sown at densities of 250, 400 and 550 thousand plants $\mathrm{ha}^{-1}$. The experiments followed a randomized block design with twenty one treatments and

\footnotetext{
Recebido para publicação em fevereiro de 2011 e aprovado em maio de 2011

${ }^{1}$ Engenheiro-Agrônomo, Doutor. Instituto Federal de Educação Ciência e Tecnologia do Rio Grande do Sul - Campus Ibirubá. Rua Nelsi Ribas Fritsch, 1111, Esperança, 98200000, Ibirubá, RS, Brasil. plmarcos1@yahoo.com.br. Autor para correspondência.

2 Engenheiro-Agrônomo, Doutor. Departamento de Fitotecnia, Av. Roraima, 1000, Camobi, 97105-900, Santa Maria, RS, Brasil. drmarcelodutra@yahoo.com.br;

${ }_{3}^{3}$ Engenheiro-Agrônomo, Doutor. Universidade Federal de Pelotas, Faculdade de Agronomia Eliseu Maciel, Departamento de Fitotecnia. Cx. Postal 354, 96010-900, Capão do Leão, RS, Brasil. orlando_lucca@ hotmail.com;

${ }^{4}$ Engenheiro-Agrônomo, Doutor. Instituto Phytus. Rua Duque de Caxias, 2319 - 2º Andar, Medianeira, 97050-010, Santa Maria, RS, Brasil. cio@institutophytus.com.br;

${ }^{5}$ Engenheiro-Agrônomo, Doutor. Syngenta Proteção de Cultivos LTDA. Av. Tiradentes, 501, torre 2, $15^{\circ}$ andar, 86010-020, Londrina, PR, Brasil. adilson.jauer@syngenta.com;

${ }^{6}$ Engenheiro-Agrônomo, Mestre. Universidade Federal de Santa Maria, Departamento de Engenharia Agrícola, Av. Roraima, 1000, Camobi, 97105-900, Santa Maria, RS, Brasil. d_uhry@ hotmail.com.
} 
four replications. The treatments were arranged in a split plot represented by cultivars in the plots, and the populations of plants in the subplots. Grain yield and the yield components pods per plant and $\mathrm{m}^{-2}, 100$-seed weight and number of seeds per plant were evaluated. The performance of conventional and Roundup Ready ${ }^{T M}$ cultivars differed with the plant stand. Under severe water stress the increase in plant stand did not affect yield. Only cultivar 'A 6001 RG' showed stable performance under different plant stands, indicating a greater plasticity of this cultivar. The number of pods per plant was reduced with the increasing the number of plants per area. The largest yields were achieved with the largest number of pods $\mathrm{m}^{-2}$. The highest 100-seed weight was found for the largest plant stand. The number of seeds per pod decreased with increasing plant stand. The most favorable growing conditions tend to increase pods $\mathrm{m}^{-2}, 100$-seed weight and number of seeds per pod.

Key words: Glycine max L. (Merrill), seed density, transgenic soybeans, yield, yield components.

\section{INTRODUÇÃO}

A cultura da soja ocupa papel importante na economia mundial, sendo cultivada em quase todas as partes do mundo. O Brasil é o segundo maior produtor mundial e o maior da América Latina. Dentro das culturas de grãos, a da soja destaca-se no cenário nacional, sendo a primeira colocada em área plantada. Estima-se que na safra de 2010/ 2011 foram cultivados cerca de 23 milhões de hectares de soja, que produziram em torno de 71 milhões de toneladas de grãos (IBGE, 2011).

A carga genética do cultivar está relacionada com o seu melhoramento, e o agricultor tem como função permitir que essa se expresse. Tanto a redução como o aumento da população de plantas quando comparados com a população indicada ou buscando a população ideal têm que ser bem estudados, pois as características intrínsecas ao genótipo e as condições ambientais interferem nos resultados. A adoção de cultivares de soja modificada pela engenharia genética pelos produtores é grande, na safra 2010/11 ultrapassou a convencional, atingindo $83 \%$ de cobertura nas lavouras, conforme os números apurados pela Expedição Safra 2010/11 (Gazeta do Povo, 2011).

A cultura da soja apresenta alta plasticidade; ou seja, capacidade de se adaptar às condições ambientais e de manejo, por meio de modificações na morfologia da planta, da arquitetura e dos componentes do rendimento, e essas modificações podem estar relacionadas com a fertilidade do solo, população de plantas e com o espaçamento entre linhas (Pires et al., 2000; Rambo et al., 2003). Por meio dessa característica pode se ter a percepção de que existe uma faixa ampla de populações de plantas, em que a variação do número de plantas não afeta a produtividade de grãos. No entanto, em muitos trabalhos os resultados divergem dessa teoria (Ball et al., 2000; Peluzio et al., 2002; Rigsby \& Board, 2003; Rezende et al., 2004; Heitholt et al., 2005; Ludwig et al., 2007).
O tema densidade de semeadura e população de plantas na soja já vem sendo pesquisado desde o inicio do cultivo dessa espécie, dessa maneira inúmeros trabalhos já foram publicados sobre o assunto. Mas a interação genótipo $\mathrm{X}$ ambiente interfere diretamente nos resultados, o que torna necessarias novas pesquisas para melhorar o desempenho da cultura da soja, principalmente quando nova tecnologia é lançada. Dessa forma, o objetivo deste trabalho foi trazer informações sobre o comportamento de cultivares de soja convencionais e Roundup $\operatorname{Ready}^{T M}(\mathrm{RR})$, quando cultivados com diferentes populações de plantas.

\section{MATERIAL E MÉTODOS}

Foram realizados três experimentos no município de Jari, RS (altitude de $441 \mathrm{~m}$, latitude $29^{\circ} 17^{\prime} 29^{\prime \prime}$ e longitude $54^{\circ} 13^{\prime}$ 26"). O município pertence à região climática planalto, com clima do tipo Cfa 1, segundo a classificação de KÖEPPEN (Moreno, 1961), onde há precipitação e temperaturas médias anuais variando de 1.558 a $1.767 \mathrm{~mm} \mathrm{e} 17,1 \mathrm{a} 17,9^{\circ} \mathrm{C}$, respectivamente, caracterizando o clima como subtropical, do ponto de vista térmico. Os dados da precipitação pluviométrica por decêndio e a temperatura média por decêndio durante a realização dos trabalhos estão na Figura 1.

O solo da área pertence à Unidade de Mapeamento Júlio de Castilhos e classifica-se como Argissolo Vermelho-Amarelo alumínico alissólico (EMBRAPA, 1999). A correção do $\mathrm{pH}$ e adubação foram feitas pelo resultado da análise do solo em concordância com o Manual de Adubação e de Calagem para os Estados do Rio Grande do Sul e Santa Catarina (Sociedade Brasileira de Ciência do Solo, 2004) para a cultura da soja.

Para a realização dos trabalhos foram utilizados diferentes cultivares com diferentes ciclos e comportamentos quanto ao acamamento. No experimento foram semeados os cultivares CEP/CD 41, de ciclo precoce (com tendência 

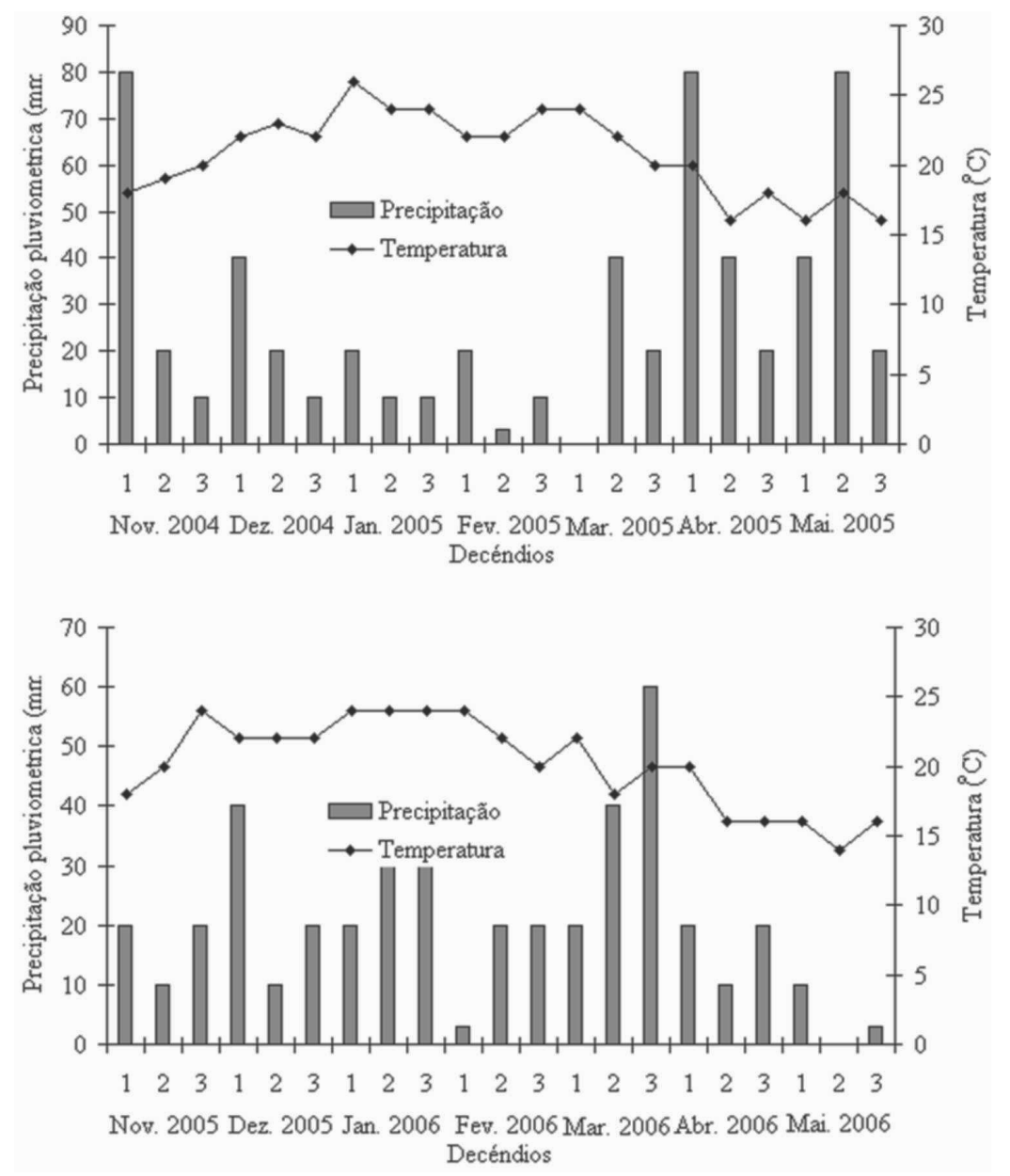

Figura 1. aPrecipitação pluviométrica por decêndio (mm) e temperatura média por decêndio ocorridas de novembro de 2004 a maio de 2005 e novembro de 2005 a maio de 2006 em Jari, RS. Fonte: INMET (2011).

a acamar); CD 201, de ciclo semiprecoce (com tendência a acamar); Fundacep 39, de ciclo médio (sem tendência a acamar); CD 205, de ciclo tardio (com tendência a acamar); e os geneticamente modificados AL72, NK Mágica 7.3 RR e A 6001 RG, estes não foram descritos no estudo, mas possuíam a campo características de precoce (A $6001 \mathrm{RG})$ a média (NK Mágica 7.3 RR e AL 72). As populações de plantas utilizadas foram: 250, 400 e $550 \mathrm{mil} \mathrm{ha}^{-1}$, assim perfazendo a indicada pela Reunião de Pesquisa de Soja da Região Sul (2004), e 150 mil plantas a mais e a menos.

Foi utilizado um espaçamento de 0,45 m entre linha, em sistema de semeadura direta. O número de sementes aptas por unidade de área foi determinado por meio da correção da correção do poder germinativo para $100 \%$ e mais $5 \%$ de margem de segurança, referente à sobrevivência das plantas. No primeiro ano os cultivares apresentavam germinação de $80 \%$ (CEP/CD 41), 92\% (CD 201), 81\% (Fundacep 39), 80\% e 79\% (CD 205), 83\% (AL72), 81\% (NK Mágica 7.3 RR) e 89\% (A 6001 RG). Já no segundo ano as porcentagens de germinação dos cultivares foram 52\% (CEP/CD 41), 89\% (CD 201), 73\% (Fundacep 39), 68\% e 71\% (CD 205), 75\% (AL72), 72\% (NK Mágica 7.3 RR) e
85\% (A $6001 \mathrm{RG}$ ). As semeaduras foram realizadas em 6 de novembro de 2004, 10 de novembro de 2005 e 3 de janeiro de 2006 (após a época indicada para a cultura, Reunião de Pesquisa de Soja da Região Sul, 2004).

Em cada ensaio o delineamento experimental utilizado foi o de blocos ao acaso, com 21 tratamentos e quatro repetições. Os tratamentos foram dispostos em um esquema de parcelas subdivididas, representados pelos cultivares, nas parcelas, e pelas populações de plantas, nas subparcelas. As subparcelas foram constituídas de cinco linhas com $5 \mathrm{~m}$ de comprimento, totalizando uma área de 11,25 m². A área útil foi de três linhas com $3 \mathrm{~m}$, totalizando $4,05 \mathrm{~m}^{2}$.

Para o controle das plantas daninhas nos cultivares de soja convencional foram aplicados os herbicidas de folha estreita (Cletodim 96g/ha +óleo mineral 0,5\% v/v) e folha larga (Bentazona 960g/ha + óleo mineral 0,5\% $/ \mathrm{v}$ ), já nos cultivares de soja transgênica foi utilizado o Glifosato $720 \mathrm{~g} / \mathrm{ha}$. Também foram executadas todas as práticas culturais recomendadas para a obtenção do máximo controle de insetos e moléstias, garantindo a condução do experimento com o mínimo de interferência desses fatores. 
Tabela 1. Quadros de análise da variância

\begin{tabular}{lcrrrrr}
\hline \multicolumn{1}{c}{ FV } & GL & Produtividade & $\begin{array}{c}\text { Legumes/ } \\
\text { planta }^{-1}\end{array}$ & $\begin{array}{c}\text { Legumes/ } \\
\mathbf{m}^{-2}\end{array}$ & $\begin{array}{c}\text { Peso de } \\
\mathbf{1 0 0}_{\text {grãos }}\end{array}$ & $\begin{array}{c}\text { Grão/ } \\
\text { legumes }^{-1}\end{array}$ \\
\hline Ano & 2 & $679,648^{*}$ & $2,232^{\mathrm{ns}}$ & $63,623^{*}$ & $244,729^{*}$ & $16,763^{*}$ \\
Cultivar & 6 & $22,497^{*}$ & $11,267^{*}$ & $3,475^{*}$ & $9,343^{*}$ & $65,106^{*}$ \\
População & 2 & $50,291^{*}$ & $51,803^{*}$ & $7,804^{*}$ & $9,810^{*}$ & $4,067^{*}$ \\
Ano*Cultivar & 12 & $10,647^{*}$ & $4,633^{*}$ & $4,230^{*}$ & $14,560^{*}$ & $10,201^{*}$ \\
Ano*População & 4 & $16,858^{*}$ & $3,020^{*}$ & $9,010^{*}$ & $0,386^{\mathrm{ns}}$ & $1,384^{\mathrm{ns}}$ \\
Cultivar* População & 12 & $2,877^{*}$ & $1,376^{\mathrm{ns}}$ & $1,531^{\mathrm{ns}}$ & $0,668^{\mathrm{ns}}$ & $1,126^{\mathrm{ns}}$ \\
Ano*Cultivar*População & 24 & $2,938^{*}$ & $1,323^{\mathrm{ns}}$ & $1,203^{\mathrm{ns}}$ & $1,165^{\mathrm{ns}}$ & $1,188^{\mathrm{ns}}$ \\
Erro & 189 & & & & & \\
\hline
\end{tabular}

(*) indicam significância a 5\% de probabilidade pelo teste $\mathrm{F}$ e ${ }^{\left({ }^{n s}\right)}$ não significativo.

Para as avaliações dos componentes do rendimento (grão por legume, peso de 100 grãos, legumes por planta e legumes $\mathrm{m}^{-2}$ ) foram coletadas plantas de $0,5 \mathrm{~m}$ linear na área útil da parcela. Para a determinação da produtividade, foram coletadas as plantas de duas linhas de três metros da área útil. Essas plantas foram posteriormente trilhadas em trilhadeira estacionária. Os grãos limpos foram pesados e determinou-se o teor de umidade, sendo a produtividade calculada em seguida, em $\mathrm{kg} \mathrm{ha}^{-1}$ a $13 \%$ de umidade.

Foi realizada análise de variância de cada ensaio e, em seguida, análise conjunta dos ensaios. A análise estatística foi feita pelo software estatístico SISVAR ${ }^{\circledR}$ (Ferreira, 2000), por meio da análise de variância para verificar os efeitos principais e as interações. Quando detectadas interações, foi realizado teste de média Tukey a 5\% de significância e análise de regressão das populações para as características estudadas em cada ano. Procurou-se chegar ao polinômio que melhor se ajustasse aos dados.

\section{RESULTADOS E DISCUSSÃO}

Foi detectada interação entre datas de semeadura, genótipo e população de plantas para produtividade de grãos (Tabela 1). Assim, as diferentes condições ambientais experimentadas pelos cultivares nos diferentes anos de trabalho resultaram em produtividades diferentes tanto dos cultivares convencionais quanto de Roundup Ready ${ }^{T M}$ nas diferentes populações de plantas.

Quando avaliado o comportamento das populações de plantas dentro de cada ano (Figura 2) foi constatado que na semeadura em 2004 não foi observado efeito significativo das populações, já nas semeaduras em novembro de 2005 e janeiro de 2006 ocorreu aumento no rendimento com o aumento da população de plantas. Rezende et al. (2004), trabalhando com diferentes populações de plantas, também constataram que a alteração na população de plantas afeta o rendimento de grãos, e explicaram esse comportamento pelo fato de a variação do espaço entre plantas pro- porcionar alterações na distribuição de luz, podendo assim contribuir de forma mais ativa no processo de fotossíntese.

Assim, o comportamento da população foi afetado pelo ano de cultivo, dessa forma o ajuste da densidade de plan-
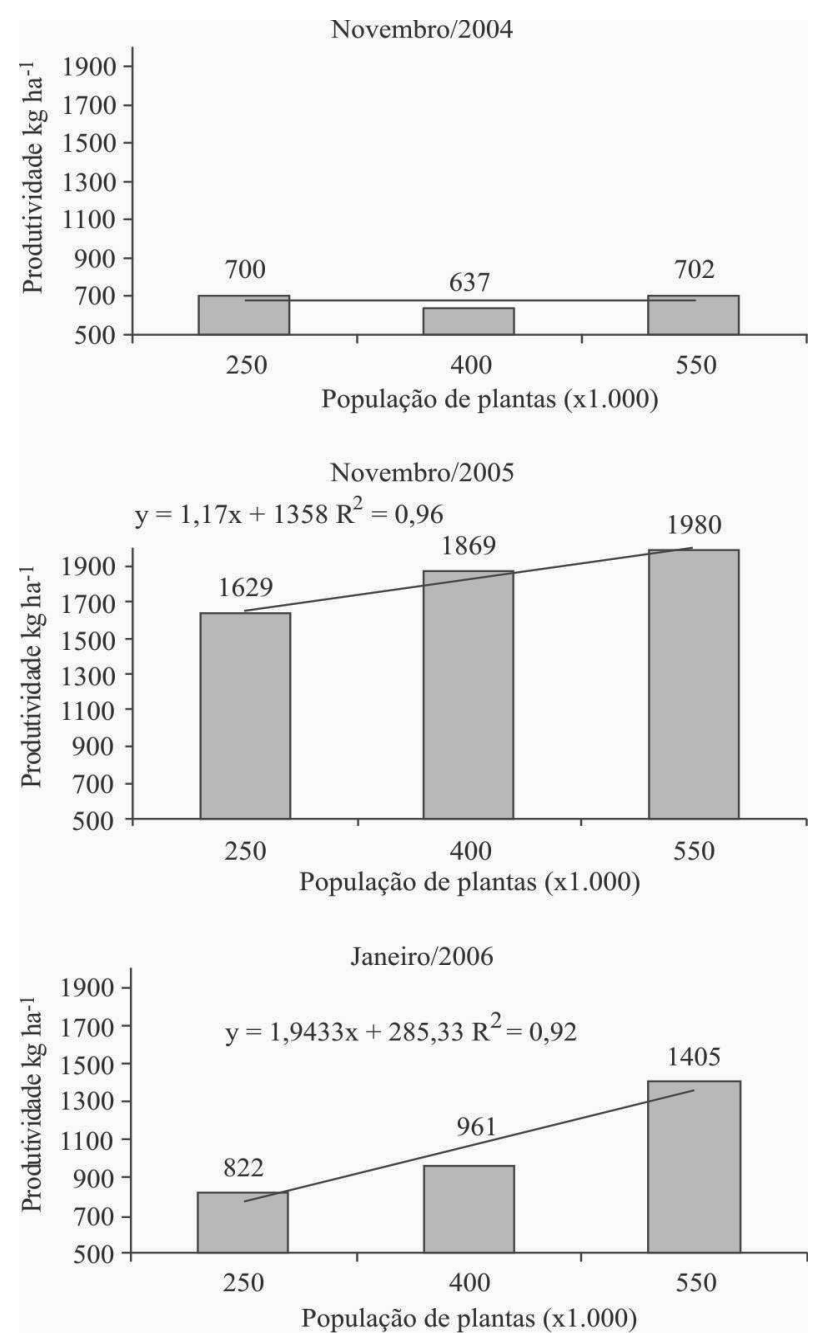

Figura 2. Produtividade de grãos $\left(\mathrm{kg} \mathrm{ha}^{-1}\right)$ em três populações de plantas $\left(250,400\right.$ e 550 mil plantas ha $\left.{ }^{-1}\right)$ e três semeaduras (novembro de 2004 e 2005 e janeiro de 2006) e média de sete cultivares (CEP/CD 41, CD 201, Fundacep 39, CD 205, AL72, NK Mágica 7.3 RR e A 6001 RG). 
tas ideal está relacionado com as condições ambientais de cada ano; pois, segundo os dados de precipitação (Figura 1), o local de instalação do experimento sofreu restrição hídrica severa durante a safra de 2004/2005, principalmente a partir do segundo decêndio de dezembro de 2004 até o segundo de março de 2005. Durante a safra de 2005/ 2006 ocorreu baixa precipitação no primeiro decêndio de fevereiro de 2006. Esses resultados permitem constatar que em condições de déficit hídrico severo ocorrido na safra 2004/2005 o aumento da população de plantas não altera o rendimento de grãos. Na safra 2005/2006 os resultados confirmam os obtidos por Kuss et al. (2008), que constataram aumento no rendimento com aumento da população de plantas. Esses pesquisadores mencionam que em maiores populações de plantas estas ficam mais adensadas, o que acarreta maior competição, levando as raízes a se aprofundarem e se espalharem mais no perfil do solo à procura de água, resultando em maior rendimento devido à maior extração de água e ao maior número de plantas. Os resultados na semeadura em janeiro de 2006 confirmam os observados por Ludwig et al. (2007), em que estes verificaram que o aumento da população de plantas em cultivo após a época indicada reduz as perdas de produtividade.

No desdobramento dos cultivares e das populações em cada ano (Tabela 2), constatou-se que no primeiro ano nenhum cultivar respondeu à alteração significativa da população de plantas. Na população de 250 mil plantas $\mathrm{ha}^{-1}$ os cultivares com maior produtividade foram Fundacep 39 (932 kg ha $\left.{ }^{-1}\right)$, CD 205 (963 kg ha-1), NK Mágica 7,3 RR

Tabela 2. Produtividade de grãos $\left(\mathrm{kg} \mathrm{ha}^{-1}\right)$ de sete cultivares (CEP/CD 41, CD 201, Fundacep 39, CD 205, AL72, NK Mágica 7.3 RR

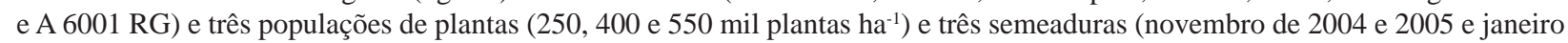
de 2006).

\begin{tabular}{lccc}
\hline & $\mathbf{2 5 0}$ & $\mathbf{4 0 0}$ & $\mathbf{5 5 0}$ \\
\cline { 2 - 4 } Cultivar & \multicolumn{3}{c}{ Rendimento grãos kg/ha $^{-1}$} \\
\cline { 2 - 3 } & \multicolumn{3}{c}{ Novembro 2004 } \\
\hline CEP/CD 41 & $545 \mathrm{bc} \mathrm{A}$ & $604 \mathrm{abc} \mathrm{A}$ & $601 \mathrm{bc} \mathrm{A}$ \\
CD 201 & $625 \mathrm{abc} \mathrm{A}$ & $661 \mathrm{abc} \mathrm{A}$ & $669 \mathrm{abc} \mathrm{A}$ \\
Fundacep 39 & $932 \mathrm{ab} \mathrm{A}$ & $712 \mathrm{abc} \mathrm{A}$ & $875 \mathrm{ab} \mathrm{A}$ \\
CD 205 & $963 \mathrm{ab} \mathrm{A}$ & $991 \mathrm{a} \mathrm{A}$ & $1.083 \mathrm{a} \mathrm{A}$ \\
A 6001 RG & $250 \mathrm{c} \mathrm{A}$ & $280 \mathrm{c} \mathrm{A}$ & $397 \mathrm{c} \mathrm{A}$ \\
AL 72 & $528 \mathrm{bc} \mathrm{A}$ & $417 \mathrm{bc} \mathrm{A}$ & $400 \mathrm{c} \mathrm{A}$ \\
NK Mágica 7.3 RR & $1.057 \mathrm{aA}$ & $797 \mathrm{ab} \mathrm{A}$ & $888 \mathrm{ab} \mathrm{A}$ \\
Média & 700 & 637 & 702 \\
\hline
\end{tabular}

\begin{tabular}{|c|c|c|c|}
\hline \multicolumn{4}{|c|}{ C.V. 22,6} \\
\hline \multicolumn{4}{|c|}{ Novembro 2005} \\
\hline CEP/CD 41 & 1.924 a A & $1.757 \mathrm{bc} \mathrm{A}$ & $1.920 \mathrm{bc} \mathrm{A}$ \\
\hline CD 201 & $1.827 \mathrm{ab} \mathrm{A}$ & $1.948 \mathrm{abc} A$ & 1.579 с A \\
\hline Fundacep 39 & $1.415 \mathrm{bc} \mathrm{B}$ & $1.648 \mathrm{bc} \mathrm{AB}$ & $1.963 \mathrm{bc} \mathrm{A}$ \\
\hline CD 205 & $1.801 \mathrm{ab} \mathrm{B}$ & 2.306 a A & $2.505 \mathrm{a} \mathrm{A}$ \\
\hline A $6001 \mathrm{RG}$ & $1.507 \mathrm{abc} \mathrm{A}$ & $1.733 \mathrm{bc} \mathrm{A}$ & 1.619 c A \\
\hline AL 72 & $1.819 \mathrm{ab} \mathrm{A}$ & $2.080 \mathrm{ab} \mathrm{A}$ & $2.001 \mathrm{bc} \mathrm{A}$ \\
\hline NK Mágica 7.3 RR & 1.107 c C & $1.613 \mathrm{c} \mathrm{B}$ & $2.274 \mathrm{ab} \mathrm{A}$ \\
\hline Média & 1.629 & 1.869 & 1.980 \\
\hline \multicolumn{4}{|c|}{ C.V. 13,1} \\
\hline \multicolumn{4}{|c|}{ Janeiro 2006} \\
\hline CEP/CD 41 & $1.027 \mathrm{ab} B$ & $1.010 \mathrm{a} \mathrm{B}$ & $1.595 \mathrm{ab} \mathrm{A}$ \\
\hline CD 201 & $1.183 \mathrm{a} \mathrm{B}$ & 1.247 a B & $1.878 \mathrm{a} \mathrm{A}$ \\
\hline Fundacep 39 & 770 ab B & 869 a B & $1.385 \mathrm{bc} \mathrm{A}$ \\
\hline CD 205 & $721 \mathrm{~b} B$ & 998 a B & $1.643 \mathrm{ab} \mathrm{A}$ \\
\hline A $6001 \mathrm{RG}$ & $792 \mathrm{ab} A$ & 906 a A & 886 d A \\
\hline AL 72 & 662 b B & 864 a B & $1.300 \mathrm{bcd} \mathrm{A}$ \\
\hline NK Mágica 7.3 RR & 597 b B & 836 a $\mathrm{AB}$ & $1.145 \mathrm{~cd} \mathrm{~A}$ \\
\hline Média & 822 & 961 & 1.405 \\
\hline \multicolumn{4}{|c|}{ C.V. 19,3} \\
\hline
\end{tabular}

Médias seguidas por mesma letra minúscula na coluna e maiúscula na linha não diferiram pelo teste de Tukey a 5\%. 
(1.057 kg ha $\left.{ }^{-1}\right)$ e CD 201 (625 kg ha'-1); no entanto, o último não diferiu dos com menor produção. Na população de plantas de 400 mil plantas ha-1 os únicos cultivares que diferiram do menor valor foram CD $205\left(991 \mathrm{~kg} \mathrm{ha}^{-1}\right)$ e NK Mágica 7,3 RR (797 kg ha $\left.{ }^{-1}\right)$. Na maior população de plantas os cultivares que diferiram da menor produtividade foram Fundacep $39\left(875 \mathrm{~kg} \mathrm{ha}^{-1}\right)$, CD $205\left(1.083 \mathrm{~kg} \mathrm{ha}^{-1}\right) \mathrm{e}$ NK Mágica 7,3 RR (888 $\left.\mathrm{kg} \mathrm{ha}^{-1}\right)$.

$\mathrm{Na}$ semeadura em novembro de 2005 os cultivares CEP/CD 41, CD 201, AL 72 e A 6001 RG mantiveram o rendimento estável, não apresentando variações significativas quando variou a população de plantas. Nessa semeadura o cultivar com maior rendimento foi CD 205, com $2.505 \mathrm{~kg} \mathrm{ha}^{-1}$ na população de plantas de $550 \mathrm{mil}$ plantas $\mathrm{ha}^{-1}$, e o menor rendimento foi observado no cultivar NK Mágica 7,3 RR, com $1.107 \mathrm{~kg} \mathrm{ha}^{-1}$ na menor população de plantas.

Na semeadura em novembro de 2005 o menor rendimento com 250 mil plantas ha ${ }^{-1}$ foi observado nos cultivares Fundacep 39 (1.415 $\left.\mathrm{kg} \mathrm{ha}^{-1}\right)$, A $6001 \mathrm{RG}\left(1.507 \mathrm{~kg} \mathrm{ha}^{-1}\right)$ e NK Mágica 7,3 RR (1.107 kg ha-1), estes mesmos cultivares, juntamente com CEP/CD 41 e CD 201, também apresentaram os menores valores de produtividade na população de plantas de 400 mil ha $^{-1}$. Resultados que apresentam divergência dos observados na primeira semeadura para os cultivares Fundacep 39 na população de 250 mil plantas ha-1 e NK Mágica 7,3 RR de 250 e 400 mil plantas $\mathrm{ha}^{-1}$, os quais tiveram maiores valores de rendimento. Este resultado pode estar relacionado com a estabilidade e adaptação dos cultivares ao ambiente, conforme relatado por Peixoto et al. (2000), pois alterações ambientais alteram o comportamento dos genótipos.

Em novembro de 2005 os cultivares CD $205(2.505 \mathrm{~kg}$ $\left.\mathrm{ha}^{-1}\right)$, AL 72 (2.001 kg ha-1) e NK Mágica 7,3 RR (2.274 kg $\left.\mathrm{ha}^{-1}\right)$ apresentam maior rendimento na população de plantas de 550 mil plantas ha-1. Observando o rendimento do cultivar NK Mágica 7,3 RR, ele apresentava um dos piores rendimentos nas outras população de plantas; no entanto, nesta um dos melhores. Aumento de $1.100 \mathrm{~kg} \mathrm{ha}^{-1} \mathrm{e}$ $600 \mathrm{~kg} \mathrm{ha}^{-1}$ em comparação à população de 250 e 400 mil plantas ha $^{-1}$, levando a considerar que a população de plantas para alguns genótipos é fator de grande importância para a obtenção de bons resultados com a cultura da soja, confirmando a teoria de Rambo et al. (2004) de que o potencial de rendimento da soja pode ser modificado pelo arranjo de plantas. Assim, estudos buscando ajustar a melhor população de plantas para cada genótipo são imprescindíveis para potencializar a produtividade.

Na semeadura tardia realizada em janeiro de 2006 somente o cultivar A 6001 RG se manteve estável, não apresentando diferença significativa na produção dentro das diferentes populações de plantas, indicando que este cultivar possui plasticidade, pois foi o único que não res- pondeu à alteração da população de plantas em todas as condições. Para Pires et al. (2000), a plasticidade é a capacidade que a planta tem de alterar sua morfologia e seus componentes de rendimento, a fim de adequá-los às condições ambiental e de manejo.

Para os demais cultivares trabalhados foi constatada a existência de um comportamento diferenciado quando estavam expostos a condições ambientais distintas. Assim, tanto os cultivares convencionais quanto os Roundup Ready ${ }^{T M}$ necessitam de ajustamento da população de plantas, o que é confirmado por Heitholt et al. (2005), que trabalharam com 10 cultivares e três populações de plantas e observaram que o comportamento dos materiais dentro das populações era modificado pelo ano de cultivo. Porém, divergem dos verificados por Bonato et al. (2001), que constataram grande semelhança entre o rendimento de grãos dos cultivares de soja indicados para cultivo no Rio Grande do Sul, quando semeados a partir do dia 10 de dezembro, mesmo que possuissem diferentes ciclos.

$\mathrm{Na}$ semeadura realizada em janeiro de 2006 o maior rendimento foi obtido pelo cultivar CD $201\left(1.878 \mathrm{~kg} \mathrm{ha}^{-1}\right)$ na maior população de plantas. Novamente, o menor rendimento foi encontrado no cultivar NK Mágica 7.3 RR (597 kg ha-1) na menor população de plantas. O maior rendimento na população de plantas de 250 mil plantas $\mathrm{ha}^{-1}$ foi obtido nos cultivares CEP/CD $41\left(1.027 \mathrm{~kg} \mathrm{ha}^{-1}\right)$, CD 201 (1.183 $\left.\mathrm{kg} \mathrm{ha}^{-1}\right)$, Fundacep $39\left(770 \mathrm{~kg} \mathrm{ha}^{-1}\right)$ e A 6001 RG (792 $\left.\mathrm{kg} \mathrm{ha}^{-1}\right)$. Na população de 400 mil plantas aptas ha $^{-1}$ não houve diferença entre cultivares, já na população de plantas de 550 mil plantas ha ${ }^{-1}$ os cultivares CEP/CD 41 (1.595 kg ha-1), CD 221 (1.878 $\left.\mathrm{kg} \mathrm{ha}^{-1}\right)$ e CD 205 (1.643 kg $\left.\mathrm{ha}^{-1}\right)$ apresentaram os maiores rendimentos.

Não ocorreu interação entre épocas de semeadura, população de plantas e genótipos tanto para o número de legumes por planta como para os legumes $\mathrm{m}^{-2}$ (Tabelas $1 \mathrm{e}$ 3 e Figura 3). Na semeadura em novembro de 2004 tanto o número de legumes por planta como o de legumes $\mathrm{m}^{-2}$ reduziram-se com o aumento da população de plantas, o que não afetou o rendimento. Já nas semeaduras em novembro de 2005 e janeiro de 2006, com o aumento da população de plantas ocorreu redução nos legumes por planta e aumento nos legumes $\mathrm{m}^{-2}$, resultado que pode explicar as produtividades mais elevadas com o aumento da população de plantas nas semeaduras em novembro de 2005 e janeiro de 2006. As maiores produtividades foram alcançadas onde foi constado maior número de legumes $\mathrm{m}^{2}$, comportamento que é explicado pela compensação entre legumes por planta e número de plantas por área. Heiffig (2002) explica que o número de legumes por planta é o componente do rendimento de grãos que mais sofre influência da população de plantas, e varia inversamente com a variação da população (Peixoto et al., 2000). 
Na semeadura em 2004 o cultivar Fundacep 39 apresentou o maior valor de legumes por planta (Tabela 3) e legumes $\mathrm{m}^{-2}$. Nesse cultivo o NK Mágica 7,3 RR também teve valores elevados em legumes $\mathrm{m}^{-2}$. Na semeadura em novembro de 2005 não foi constatada diferença entre cultivares para legumes por planta e legumes $\mathrm{m}^{-2}$. Na semeadura em janeiro de 2006 os cultivares CD 221, Fundacep
39 e CD 205 tiveram os valores mais elevados de legumes por planta. No entanto, para legumes $\mathrm{m}^{-2}$, além desses cultivares, o CEP/CD 41 e AL 72 também apresentaram valores elevados.

A variável peso de 100 grãos foi afetada pelas densidades de plantas e pela interação ano x cultivar (Tabelas 1 e 3 e Figura 4). O maior valor foi encontrado na maior população

Tabela 3. Legumes por planta, legumes $\mathrm{m}^{-2}$, peso de 100 grãos (g) e grãos por legume de sete cultivares (CEP/CD 41, CD 201, Fundacep 39, CD 205, AL72, NK Mágica 7.3 RR e A 6001 RG) e três populações de plantas $\left(250,400\right.$ e 550 mil plantas/ha $\left.{ }^{-1}\right)$ e três semeaduras (novembro de 2004, 2005 e janeiro de 2006).

\begin{tabular}{|c|c|c|c|}
\hline \multirow{2}{*}{ Cultivar } & Novembro 2004 & Novembro 2005 & Janeiro 2006 \\
\hline & \multicolumn{3}{|c|}{ Legumes por planta } \\
\hline CEP/CD 41 & $18,08 \mathrm{~b} \mathrm{~A}$ & 20,15 a A & 16,68 c A \\
\hline CD 201 & 12,19 b B & 18,10 a B & $24,75 \mathrm{ab} \mathrm{A}$ \\
\hline Fundacep 39 & 28,30 a A & 23,44 a A & 26,72 a A \\
\hline CD 205 & 14,17 b B & 16,70 a B & $24,62 \mathrm{ab} \mathrm{A}$ \\
\hline A $6001 \mathrm{RG}$ & $13,28 \mathrm{~b} \mathrm{~A}$ & 16,83 a A & $17,03 \mathrm{bc} \mathrm{A}$ \\
\hline AL 72 & 15,98 b A & 19,00 a A & 13,82 c A \\
\hline NK Mágica 7.3 RR & $18,95 \mathrm{~b} \mathrm{~A}$ & 17,08 a $\mathrm{AB}$ & 11,57 c B \\
\hline Média & 17,2 & 18,7 & 19,3 \\
\hline \multicolumn{4}{|c|}{ C.V. 34,9} \\
\hline Cultivar & & Legumes $\mathbf{m}^{-2}$ & \\
\hline CEP/CD 41 & $435 \mathrm{bc} B$ & 662 a A & $480 \mathrm{ab} B$ \\
\hline CD 201 & 362 c B & 585 a A & 555 a A \\
\hline Fundacep 39 & 683 a A & 694 a A & $413 \mathrm{ab} B$ \\
\hline CD 205 & 481 bc B & 685 a A & $398 \mathrm{ab} B$ \\
\hline A $6001 \mathrm{RG}$ & 373 bc B & 602 a A & 353 b B \\
\hline AL 72 & 442 bc B & 715 a A & $442 \mathrm{ab} B$ \\
\hline NK Mágica 7.3 RR & $544 \mathrm{ab} B$ & 708 a A & 317 b C \\
\hline Média & 474 & 665 & 422 \\
\hline \multicolumn{4}{|c|}{ C.V. 28,1} \\
\hline Cultivar & \multicolumn{3}{|c|}{ Peso de 100 grãos (g) } \\
\hline CEP/CD 41 & 9,23 с C & 15,88 a A & $13,76 \mathrm{ab} B$ \\
\hline ‘CD 201 & 11,02 b C & 15,54 a A & 13,12 b B \\
\hline Fundacep 39 & 12,72 a B & 15,67 a A & $13,98 \mathrm{ab} B$ \\
\hline CD 205 & 13,30 a $\mathrm{AB}$ & 13,74 b A & 12,39 b B \\
\hline A $6001 \mathrm{RG}$ & 7,90 с B & $15,18 \mathrm{ab} A$ & 14,95 a A \\
\hline 'AL 72' & 9,14 с C & 15,78 a A & $13,82 \mathrm{ab} B$ \\
\hline NK Mágica 7.3 RR & $12,58 \mathrm{ab} B$ & 16,10 a $\mathrm{A}$ & 14,98 a A \\
\hline Média & 10,84 & 15,41 & 13,86 \\
\hline \multicolumn{4}{|c|}{ C.V. 10,1} \\
\hline Cultivar & \multicolumn{3}{|c|}{ Grãos por legume } \\
\hline CEP/CD 41 & 2,22 a $\mathrm{A}$ & $2,11 \mathrm{bc} \mathrm{A}$ & 2,24 a A \\
\hline CD 201 & 2,25 a A & $2,21 \mathrm{~b} \mathrm{~A}$ & 2,11 a $\mathrm{A}$ \\
\hline 'Fundacep 39' & 1,98 b A & $2,05 \mathrm{bcd} A$ & $1,56 \mathrm{~d} \mathrm{~B}$ \\
\hline CD 205 & 2,36 a A & 2,46 a A & $2,08 \mathrm{ab} \mathrm{B}$ \\
\hline A $6001 \mathrm{RG}$ & $1,90 \mathrm{bc} \mathrm{A}$ & $1,91 \mathrm{~cd} \mathrm{~A}$ & $1,92 \mathrm{bc} \mathrm{A}$ \\
\hline AL 72 & 1,76 c B & $1,98 \mathrm{~cd} \mathrm{~A}$ & $1,86 \mathrm{c} \mathrm{AB}$ \\
\hline NK Mágica 7.3 RR & $1,90 \mathrm{bc} \mathrm{A}$ & $1,78 \mathrm{~d} A$ & $1,88 \mathrm{c} \mathrm{A}$ \\
\hline Média & 2,06 & 2,07 & 1,95 \\
\hline \multicolumn{4}{|c|}{ C.V. 7,0} \\
\hline
\end{tabular}

Médias seguidas por mesma letra minúscula na coluna e maiúscula na linha não diferiram pelo teste de Tukey a 5\%. 

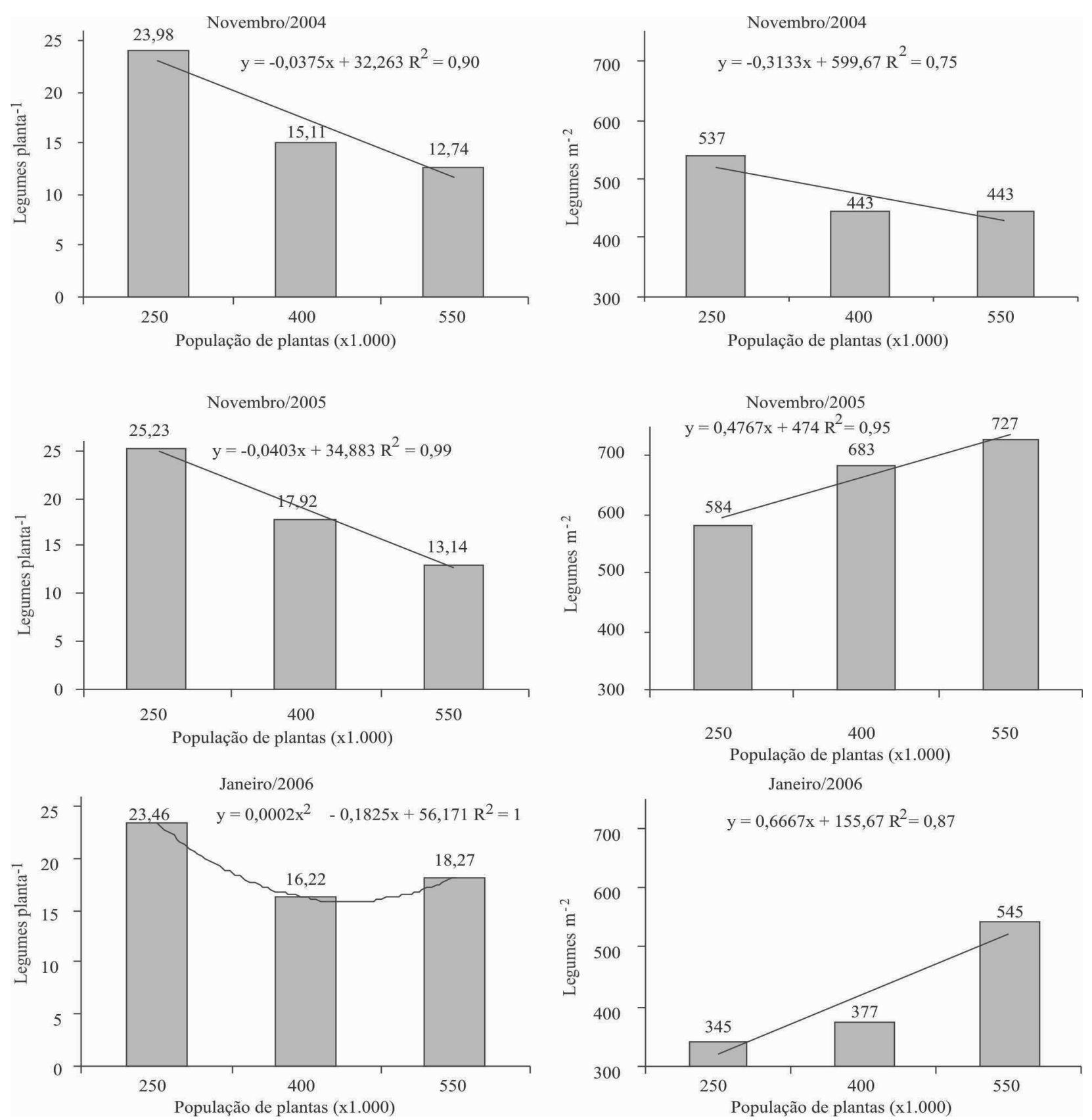

Figura 3. Legumes por planta em três populações de plantas (250, 400 e 550 mil plantas/ha ${ }^{-1}$ ) e três semeaduras (novembro de 2004 e 2005 e janeiro de 2006) e média de sete cultivares (CEP/CD 41, CD 201, Fundacep 39, CD 205, AL72, NK Mágica 7.3 RR e A 6001RG).
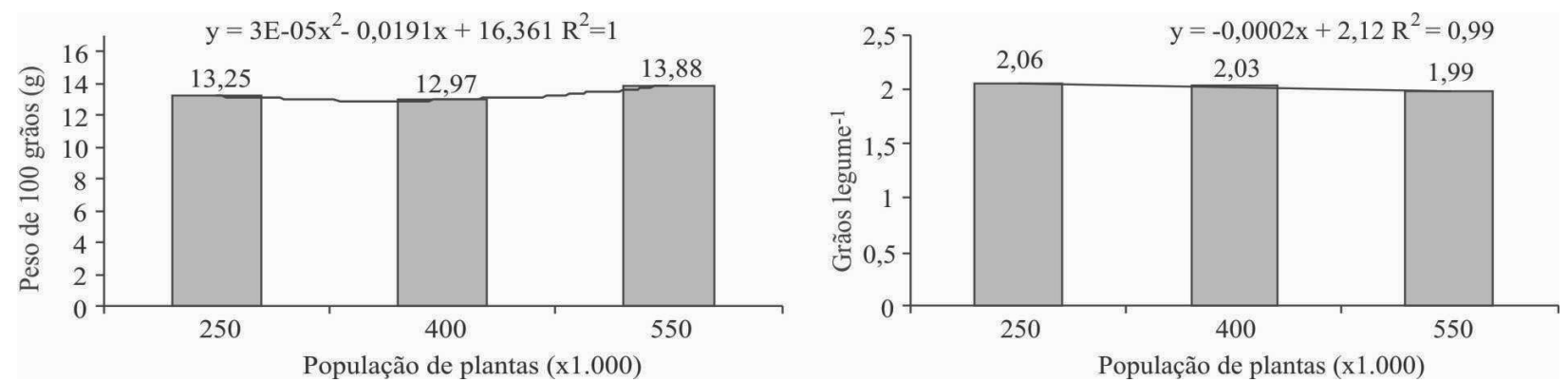

Figura 4. Peso de 100 grãos (g) e número de grãos por legume em três populações de plantas $\left(250,400\right.$ e 550 mil plantas/ha $\left.{ }^{-1}\right)$, média de três semeaduras (novembro de 2004 e 2005 e janeiro de 2006) e sete cultivares (CEP/CD 41, CD 201, Fundacep 39, CD 205, AL72, NK Mágica 7.3 RR e A 6001 RG).

Rev. Ceres, Viçosa, v. 58, n.3, p. 305-313, mai/jun, 2011 
de plantas; resultado que é explicado por Kuss et al. (2008) ao relacionar o maior peso de grãos com o menor número de legumes por planta, o que é observado na maior população de plantas. Nessa condição as plantas acumulam mais massa seca em seus grãos, do que as plantas com maior número de legumes, em que é maior a demanda por fotoassimilados. Casagrande et al. (2001) explicam esse comportamento como sendo um mecanismo de tolerância ao déficit hídrico, com direcionamento do fluxo de compostos para os legumes que se apresentam mais adiantados no processo de desenvolvimento e que, em teoria, teriam maiores chances de produzir sementes viáveis.

O número de grãos por legume foi afetado pela população de plantas. Na interação ano x cultivar (Tabelas $1 \mathrm{e}$ 3 e Figura 4) ocorreu redução no número de grãos com o aumento da população de plantas, resultado que entra em contradição com os apresentados por Heiffig (2002), o qual constatou que o número de grãos por legume é uma característica tipicamente genética e que não sofre influência de tratamentos.

Nas épocas de semeadura o número de legumes por planta (Tabela 3) foi alterado nos cultivares CD 201, CD 205 e NK Mágica 7.3 RR. Os dois primeiros apresentaram os maiores números de legumes na semeadura em janeiro de 2006; no entanto, o último alcançou maior valor na semeadura em novembro de 2004. Para as variáveis legumes $\mathrm{m}^{-2}$, peso de 100 sementes e número de grãos por legume ocorreu tendência dos maiores valores serem obtidos na semeadura em novembro de 2005. Para peso de 100 grãos e número de grãos por legume os resultados são semelhantes aos observados por Ludwig et al. (2007), os quais constataram maiores valores dessas características na semeadura em dezembro em comparação à em janeiro. Resultado que, possivelmente, esteja relacionado às melhores condições ambientais que favoreceram o desempenho superior nessa condição de cultivo (Figura 1).

\section{CONCLUSÕES}

O comportamento dos cultivares convencionais e Roundup Ready ${ }^{T M}$ diferiu com a população de plantas. Em condição de estresse hídrico severo o aumento da população de plantas não afetou a produtividade. Somentes do cultivar A 6001 RG apresentaram rendimento estável nas diferentes populações de plantas, indicando que esse cultivar possui maior plasticidade.

O número de legume por planta foi reduzido com o aumento do número de plantas por área. As maiores produtividades foram alcançadas onde foi constatado maior número de legumes $\mathrm{m}^{-2}$. O maior valor do peso de 100 grãos foi encontrado na maior população de plantas. $\mathrm{O}$ número de grãos por legume reduziu-se com o aumento da população de plantas.
Condições de cultivo mais favoráveis tendem a aumentar o número de legumes $\mathrm{m}^{-2}$, peso de 100 sementes e número de grãos por legume.

\section{REFERÊNCIAS}

Ball RA, Purcell LC, Vories ED (2000). Optimizing soybean plant population for a short-season production system in the southern USA. Crop Science, 40:757-764.

Bonato ER, Lange CE \& Ertagnolli P F (2001) Desempenho de cultivares de soja de diferentes ciclos em Semeaduras de dezembro, na região do planalto médio do rio Grande do sul. Ciência Rural, 31:935-940.

Casagrande EC, Farias JRB, Neumaier N, Oya T, Pedroso J, Martins PK, Breton MC \& Nepomuceno AL (2001) Expressão gênica diferencial durante déficit hídrico em soja. Revista Brasileira de Fisiologia Vegetal, 13:168-184.

EMBRAPA (1999). Sistema Brasileiro de Classificação de Solos. Brasília, EMBRAPA Solos. 412p.

Ferreira DF (2000) Manual do sistema Sisvar para análises estatísticas. Lavras, Universidade Federal de Lavras. 69p.

Gazeta Do Povo. Safra transgênica - Expedição Safra 2010/11. Disponível em: <http://www.gazetadopovo.com.br/blog/ expedicaosafra/?mes=201011 >, Acessado em: 09 de maio de 2011.

Kuss RCR, König O, Dutra LMC, Bellé RA, Roggia, S \& Sturmer, G. R. (2008) Populações de plantas e estratégias de manejo de irrigação na cultura da soja. Ciência Rural, 38:1133-1137.

Heiffig LS (2002) Plasticidade da cultura da soja (Glycine max, (L.) Merrill) em diferentes arranjos espaciais. Dissertação de Mestrado. Escola Superior de Agricultura "Luiz de Queiroz", Piracicaba, 81p.

Heitholt JJ, Farr JB \& Eason R (2005) Planting Configuration x Cultivar Effects on Soybean Production in Low-Yield Environments. Crop Science, 45:1800-1808.

IBGE - Confronto das Safras de 2010 e 2011 - Brasil. Disponível em: <http://www1.ibge.gov.br/home/estatistica/indicadores/ agropecuaria/lspa/1spa_201103_5.shtm>. Acessado em: 08 maio de 2011 .

INMET Mapas do Boletim Agroclimatológico. Disponível em: <http://www.inmet.gov.br/html/agro.html>. Acessado em: 09 maio de 2011.

Ludwig MP, Dutra LMC, Zabot L, Jauer A, Uhry D, Farias JR, Losekann ME, Stefanelo C \& Lucca Filho OA (2007) Efeito da densidade de semeadura e genótipos no rendimento de grãos e seus componentes na soja semeada após a época indicada. Revista da FZVA, 14:13-22.

Moreno JA (1961) Clima do Rio Grande do Sul. Secretaria de Agricultura. Porto Alegre, Diretoria de terras e colonização, Seção de geografia. 43p.

Peixoto CP, Câmara GMDES, Martins MC, Marchiori LFS, Guerzoni RA \& Mattiazzi, P. (2000) Época de semeadura e densidade de plantas de soja: I. componentes da produção e rendimento de grãos. Scientia Agricola, 57:89-96.

Peluzio, J. M, Barros HB, Santos MM dos, Reis MS dos, Rocha RNC \& Silva RR da (2002) Comportamento de duas cultivares de soja em diferentes populações de plantas, sob condições de várzea irrigada, no sul do estado do Tocantins. Agricultura Tropical, 6:69-80.

Pires JLF, Costa JA, Thomas AL \& Maehler AR (2000) Efeitos de populações e espaçamentos sobre o potencial de rendimento da soja durante a ontogenia. Pesquisa Agropecuária Brasileira, 35:1541-1547. 
Rambo L, Costa JA, Pires, JLF; Parcianello G \& Ferreira FG (2003). Rendimento de grãos da soja em função do arranjo de plantas. Ciência Rural, 33:405-411.

Rambo L, Costa JA, Pires, JLF; Parcianello G \& Ferreira FG (2004) Estimativa do potencial de rendimento por estrato do dossel da soja, em diferentes arranjos de plantas. Ciência Rural, 34:3340 .

Reunião De Pesquisa Da Soja Da Região Sul (2004) Indicações técnicas para a cultura da soja no Rio Grande do Sul e em Santa Catarina 2004/2005, Passo Fundo, Reunião de Pesquisa da Soja da Região Sul. 172p.
Rezende PM de, Grisc F, Gomes LL, Tourino MCC \& Botrel EP (2004) Efeito da semeadura a lanço e da população de plantas no rendimento de grãos e outras características da soja [Glycine $\max ($ L.) Merrill]. Ciências Agrotécnicas, 28: 499-504.

Rigsby B \& Board J.E (2003) Identification of soybean cultivars that yield well at low plant populations. Crop Science, 43:234239.

Sociedade Brasileira De Ciência Do Solo - Comissão de Química e Fertilidade do Solo (2004) Manual de Adubação e Calagem para os Estados do Rio Grande do Sul e Santa Catarina. $10^{\circ}$ ed. Porto Alegre, Sociedade Brasileira De Ciência Do Solo. 400p. 